\title{
Microwave assisted multiwall carbon nanotubes enhancing Cd(II) adsorption capacity in aqueous media
}

\author{
N.M. Mubarak a,b, J.N. Sahu ${ }^{\text {a,c,* }}$, E.C. Abdullah ${ }^{\text {d, N.S. Jayakumar }}{ }^{\text {a }}$, P. Ganesan ${ }^{\text {e }}$

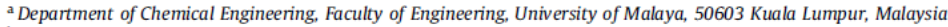 \\ ${ }^{\mathrm{b}}$ Department of Chemical and Petroleum Engineering, Faculty of Engineering, UCSI University, 56000 Kuala Lumpur, Malaysia \\ 'Petroleum and Chemical Engineering Programme Area, Faculty of Engineering, Institut Teknologi Brunei, Tungku Gadong, P.O. Box 2909, Brunei Darussalam \\ ${ }^{\mathrm{d}}$ Malaysia-Japan International Institute of Technology (MIIIT), Universiti Teknologi Malaysia, Jalan Semarak, 54100 Kuala Lumpur, Malaysia \\ ${ }^{e}$ Department of Mechanical Engineering, Faculty of Engineering, University of Malaya, 50603 Kuala Lumpur, Malaysia
}

\section{A R TICLE INFO}

Article history:

Received 28 June 2014

Received in revised form 3 September 2014

Accepted 5 September 2014

Available online 16 September 2014

\section{Keywords:}

Microwave

Heavy metal

Adsorption

Adsorption

Separation

Cancis
A B S T R A C T
Novel multiwall carbon nanotubes (MWCNTs) have been successfully synthesized using tubular
microwave chemical vapour deposition technique and proved to be an outstanding adsorbent for the
removal of Cd(II) from aqueous solution. The effect of process parameters such as pH, MWCNTs dosage,
agitation speed and time were investigated. The maximum adsorption capacities of Cd(II) were found to
be $88.62 \mathrm{mg} / \mathrm{g}$ and a statistical analysis reveals that the optimum conditions for the highest removal
(98\%) of Cd(II) are at pH 5, MWCNTs dosage $0.1 \mathrm{~g}$, agitation speed and time of $160 \mathrm{rpm}$ and 50 min,
respectively with the initial concentration of $10 \mathrm{mg} / \mathrm{L}$. The Langmuir and Freundlich isotherm models
match the experimental data very well and adsorption kinetic obeyed pseudo-second order. Our results
proved that MWCNTs can be used as an effective Cd(II) adsorbent due to the high adsorption capacity as
well as the short adsorption time needed to achieve equilibrium.
c 2014 The Korean Society of Industrial and Engineering Chemistry. Published by Elsevier B.V. All rights reserved.

\section{Introduction}

New era industries have immensely improved the living standard of human being. But however, these modern industries also pose serious adverse impacts on our living surrounding. One of the major environmental concerns is the water pollution by the heavy metals. Heavy metals in water are the main preoccupation for many years because of the toxicity towards aquatic-life, human beings and al so the environment [1]. Even though trace amounts of heavy metals are vital for the human body, they are considered as harmful when they become excessive. Contrasting with organic pollutants, most of which are susceptible to biological degradation, heavy metal ions do not end product that is harmless to the environment. The contamination of crucial concern includes lead, cadmium, mercury, zinc, chromium, silver, Tin, and other

\footnotetext{
* Corresponding author at: Department of Chemical Engineering, Faculty of Engineering, University of Malaya, 50603 Kuala Lumpur, Malaysia.

el.: +60 39101880x5004; fax: +60 391323663.

E-mail addresses: mubarak.yaseen@gmail.com (N.M. Mubarak), jay_sahu@yahoo.co.in (J.N. Sahu).
}

mutagenic nature which also makes up the earth's surface [26]. Contamination of heavy metals exists in aqueous wastes of various industries, such as mining operations, tanneries, metal plating, alloy industries and smelting [7]. A process involving industries such as metal plating and battery manufacturing can be counted as the primary source for cadmium pollution in water [8]. Cadmium is heavy metal ion which is vastly known as one of the toxic material which can be exposed to mankind either in the environment or at work. Due to the low rate of excretion of body, cadmium has a long biological half-life [9]. This explains why, if it is absorbed in one's body, cadmium remains there and accumulates throughout life. Primarily, Cadmium affects the kidney, specifically to the proximal tubular cell, main site of accumulation. Moreover, prolonged exposures to cadmium cause toxicity due to accession over time in various body tissues, including liver, chronic disorders like 'itai-itai diseases, renal damages and emphysema $[10,11]$. The World Health Organization recommended the drinking water guideline value to be $0.005 \mathrm{mg} \mathrm{Cd} / \mathrm{L}$ [12]. Cadmium and certain cadmium compounds are probable or suspected carcinogens, hence, it is compulsory to remove cadmium from drinking and waste waters.

http://dx.doi.org/10.1016/j.jiec.2014.09.005

1226-086X/@ 2014 The Korean Society of Industrial and Engineering Chemistry. Published by Elsevier B.V. All rights reserved. 
Various chemical removal methods have been utilized and also further developed over the decades to take charge of the heavy metal contaminations. Removal of heavy metal from aqueous solution consists of physical, chemical and biological techniques. Suggested conventional methods are electrochemical treatment, chemical precipitation, membrane technologies and adsorption on activated carbon [13]. Amongst all the methods, adsorption on activated carbon is considered to be very promising in terms of its efficiency of removal from aqueous solutions [14]. In addition, it is another good method to be taken into account from the aspect of handling methods and economics. Even though there are so many adsorbents available, researchers had to come up with a new adsorbent as the existing adsorbents were lacking in its efficiency to remove metal ions [15].

Carbon nanotubes (CNTs) are a new member in carbon family, essentially a new type of adsorbents that proves to retain great potential for removal of pollutants such as herbicides, chloro-benzenes, as well as lead and cadmium ions [11]. CNTs consist of a hollow and layered structure along with a large specific surface area [16] which leads to a remarkable application as an adsorbent with a high adsorption capacity for water treatment by utilizing the adsorption method. Hence, nanomaterial proves to be an essential adsorbent due to its high specific surface area along with efficient active sites for adsorption of $\mathrm{Cd}(\mathrm{II})$ from water. CNTs have a relatively larger specific are that provides a good opportunity for the removal of heavy metals [17-19]. Carbon based nanomaterial was opted to provide an alternative method for water treatment and few of these materials provided an astonishing outcome with a high rejection of contaminant from water Carbon nanotubes based technologies found its water-treatment applications in various fields, for instance, as sorbents, catalyst, filters, or membranes [17]. It is of common interest that the development of a new technique for an efficient and the selective synthesis of carbon nanotubes at the cheapest possible cost [20]. One of such possibility is the use of microwave radiation. The reason behind the choice of microwave used to produce carbon nanotubes is the novelty of this method [21]. Microwave-assisted modification of carbon nanotube is non-invasive, simple, fast, environmentally friendly and clean method as compared to traditional methods. Usually, the use of the microwave facilitates and accelerates reactions, often improving relative yields [22]. The use of microwave radiation in the synthesis and functionalization of carbon nanotubes or other nanostructures is advantageous because it provides a fast and uniform heating rate that can be selectively directed towards a targeted area compared to the conventional method used. In our innovation microwaveassisted synthesis, including fast multiwall carbon nanotube (MWCNTs) growth and ambient reaction condition, lowers the cost, and simplifies the procedure leading to a high yield synthesis of high-quality MWCNTs with minimal impurity. Unlike conventional heating, microwave heating has a higher heating rate, which results from the intrinsic transition of electromagnetic energy to thermal energy by a molecular interaction with the electromagnetic field, rather than heat transfer by conduction or convection.

In this research, a novel MWCNTs was synthesized using tubular microwave chemical vapour deposition. The developed MWCNTs tested for Cd(II) adsorption capacity in aqueous media, also a statistical optimization of process parameters such $\mathrm{pH}$, MWCNTs dosage and agitation speed and time of removal of Cd(II) were investigated. The studies on the isotherm kinetic and isotherm model were developed and investigated as well. The thermodynamic parameters and desorption studies were investigated as well.

\section{Materials and methods}

\section{Experimental setup for MWCNTs production}

The schematic of tubular microwave chemical vapor deposition (TM-CVD) for MWCNTs production as described in my previous work [23]. The horizontal tubular microwave model SynothermT1500, China reactor for production of MWCNTs. It comprised a quartz tube of $55 \mathrm{~mm}$ OD, $50 \mathrm{~mm}$ ID and $615 \mathrm{~mm}$ length. Ferrocene catalyst was placed at the entrance of the chamber and quartz boat size was placed at middle of the reaction chamber. The system was initially flushed with $\mathrm{Ar}$ in order to ensure an oxygen free environment. The gas flow rate of $\mathrm{C}_{2} \mathrm{H}_{2}$ and $\mathrm{H}_{2}$ was free mixed before entering into the tubular microwave chamber using gas mixture Model KM-20-2, Germany, after the gas mixture was sent to microwave chamber. The reaction was carried on for the desired time period and on completion, the total amount of MWCNTs produced in the quartz boats was collected and weighed. The optimized conditions for the high weight of MWCNTs production was at $900 \mathrm{~W}$ microwave power, 35 min radiation time and 0.6 gas ratio of $\mathrm{C}_{2} \mathrm{H}_{2} / \mathrm{H}_{2}$. The optimized produced MWCNTs have high BET $206 \mathrm{~m}^{2} / \mathrm{g}$ surface area having a particle size of $450 \mu \mathrm{m}$ that leads to high efficiency in removal of Cd(II) from aqueous solution.

\section{Preparation of stock solutions}

Analytical grade $\mathrm{Cd}(\mathrm{II})$ standard solution which was obtained from Merck was used to prepare stock solutions containing $1000 \mathrm{mg} / \mathrm{L}$ of Cd(II) metal ions which were further diluted with distilled water to obtain the required concentrations. As for this research, the initial concentration of $\mathrm{Cd}(\mathrm{II})$ metal ions was set to $10 \mathrm{mg} / \mathrm{L}$ and the prepared solution were used for batch adsorption experiments.

\section{Batch adsorption experiment}

A batch adsorption experiment was performed by using $100 \mathrm{~mL}$ of $10.0 \mathrm{mg} / \mathrm{L}$ of $\mathrm{Cd}(\mathrm{II})$, agitated with varying dosages of MWCNTs and other variable parameters according to the design obtained from the Design of Expert (DOE). The parameters used for this research is as shown in Table 1 . The initial pH of the stock solution was adjusted by using $1.0 \mathrm{M}$ of $\mathrm{NaOH}$ by adding in a few drops of the alkaline solution in the $100 \mathrm{~mL}$ of $10 \mathrm{mg} / \mathrm{L}$ of $\mathrm{Cd}(\mathrm{II})$ until the desired $\mathrm{pH}$ was obtained. The MWCNTs were then added into the $100 \mathrm{~mL}$ of $10 \mathrm{mg} / \mathrm{L}$ of Cd(II) solutions and it was agitated according to the parameters displayed in Table 1 . At the end of each interval of the time, the suspensions were shaken and centrifuged at $4000 \mathrm{rpm}$ for $10 \mathrm{~min}$ and the supernatant was withdrawn and filtered by using qualitative filter paper having a pore size of $3 \mu \mathrm{m}$. The filtrates were analyzed for contaminants by ICP-OES (PerkinElmer 7000 DV) in an air-argon flame using PerkinElmer multimetal standard solutions. By ICP-OES, the metals in water sample can be analysed. It detects the concentration of $\mathrm{Cd}(\mathrm{II})$ in ppm level in the solution and volume of sample required is only $1 \mathrm{~mL}$ for one analysis. The experimental errors of ICP-OES were within the range of $\pm 2.461 \%$ to $\pm 2.983 \%$. The Cd(II) residual concentrations were measured from the standard calibration

Table 1

Experimental design for batch adsorption.

\begin{tabular}{lllccll}
\hline Factor & Name & Units & Low & High & Low coded & High coded \\
\hline 1 & pH & & 4 & 6 & -1 & 1 \\
2 & CNTs dosage & $\mathrm{g}$ & 0.05 & 0.15 & -1 & 1 \\
3 & Agitation Speed & rpm & 120 & 200 & -1 & 1 \\
4 & Contact Time & min & 20 & 80 & -1 & 1 \\
\hline
\end{tabular}


curve. All the data presented are the average of three replicates. Differences between the initial and the equilibrium metal ion concentrations determine the amount of metal ions being adsorbed. The adsorption capacity of MWCNTs at a specific time, $t$ as for the adsorption kinetic study were calculated by using Eq. (1) while the adsorption equilibrium for Cd(II) was determined by Eq. (2).

$q_{t}(\mathrm{mg} / \mathrm{g})=\frac{\left(C_{o}-C_{t}\right) V}{m}$

$q_{e}(\mathrm{mg} / \mathrm{g})=\frac{\left(C_{o}-C_{e}\right) V}{m}$

where $C_{o}$ represent the initial concentration of $\mathrm{Cd}(\mathrm{II})$ solution $(\mathrm{mg}$ $\mathrm{L}), q_{t}$ represents the concentration of $\mathrm{Cd}(\mathrm{II})$ at time $t(\mathrm{mg} / \mathrm{g}), C_{e}$ represents the equilibrium concentration of $\mathrm{Cd}(\mathrm{II})(\mathrm{mg} / \mathrm{L})$ respectively, $V$ represents the volume of $\mathrm{Cd}(\mathrm{II})$ stock solution (L) and $m$ indicates the weight of the adsorbent used ( $g$ ).

Adsorption isotherms were studied by adding $0.1 \mathrm{~g}$ of the adsorbents into $100 \mathrm{~mL}$ solution with initial pH values of 5.0 and Cd(II) concentrations from 10 to $80 \mathrm{mg} / \mathrm{L}$. After the suspension were shaken for $2 \mathrm{~h}$, the $\mathrm{Cd}(\mathrm{II})$ concentration in the solution was measured and the amount of $\mathrm{Cd}(\mathrm{II})$ adsorbed at equilibrium was calculated using the above Eqs. (1) and (2).

\section{Characterization of MWCNTS}

The physical structure and morphology of the MWCNTs had been examined by the field emission scanning electron microscope (FESEM). All pH measurements were carried out using Mettler
Toledo type (MP220 model, USA). The heavy metal ion concentrations were measured by Inductively Couple Plasma (ICP) at $228.802 \mathrm{~nm}$ Cd(II)

\section{Results and discussion}

Characterization MWCNTs with and without adsorption of Cd(II)

Fig. 1(a)-(d) represents the characterization of optimum MWCNTs produced using microwave heating before and after adsorption of Cd(II) which was examined by Field Emission Scanning Electron Microscopy (FESEM) (Zeiss, Auriga). Fig. 1(a) and (b) FESEM images at different magnifications, i.e. 1000 and 1000,000 nm scales. These produced CNT is free from impurity was observed from the all the images and clear MWCNTs was observed. It also shows that these MWCNT are tens of microns long with uniform diameters. The bulk morphology of long MWCNT is filmed like and oriented. The produced MWCNTs have the vertical alignment of CNT could be observed with the diameter of CNTs ranging from 13 to $20 \mathrm{~nm}$. These images indicate that despite the long growth time and centimetre length, the tubes grew vertically without any interruption until the catalyst activity was terminated. The uniform diameter of CNTs shows that MWCNTs produced were in homogenized form. These results are in good agreement with previous researchers [24-26]. On the other hand, Fig. 1(c) and (d) represents the characterization for after adsorption of Cd(II) with a different magnification of 1000 and $1,000,000 \mathrm{~nm}$ scale. In general, after the adsorption process tube was swill from an open end of the MWCNTs tube where functiona groups such as hydroxyl or carboxyl groups which were formed
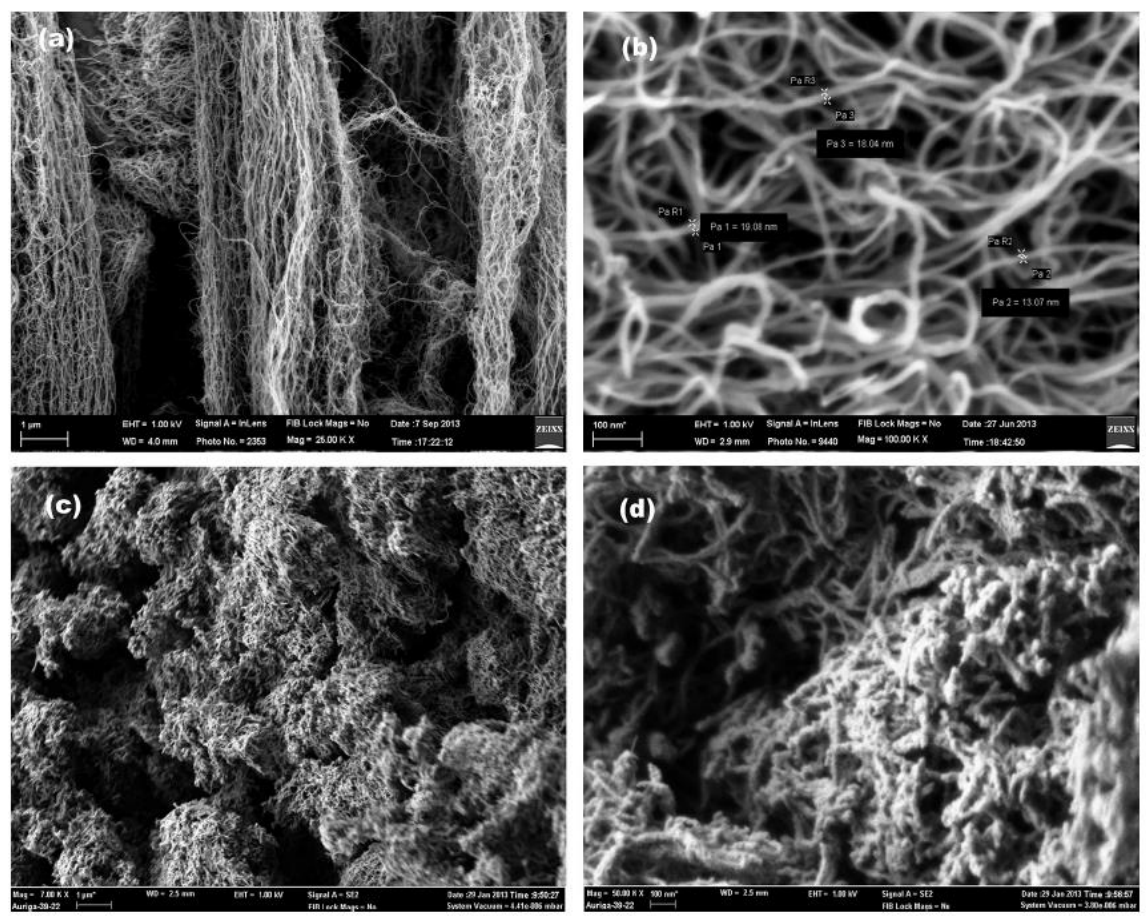

Fig. 1. FESEM images of optimum MWCNTs produced ( $a$ and $b$ ) before and ( $c$ and d) after adsorption 
through the adsorption process will attach to it or to any other available defect sites [27]. Hence, the surface of MWCNTs after adsorption will be less smooth than before adsorption MWCNTs due to the modification of MWCNTs surface after adsorption $[28,29]$.

\section{FTIR analysis of Cd(II) adsorption}

The surface chemistry in terms of functional group which is adhered to the surface of MWCNTs during the adsorption of $\mathrm{Cd}(\mathrm{II})$ process can be classified by employing Fourier Transform Infrared (FTIR) spectroscopy (Bruker, IFS66 v/S). As for this research, FTIR was engaged as well to determine the functional groups attached on the before and after adsorption of $\mathrm{Cd}(\mathrm{II})$. Microwave assisted synthesis of MWCNTs having a high BET surface area with high quality of CNTs produced were reported in previous study [23]. Adsorption behaviour of any adsorbent is influenced by the chemical reactivity of the surface especially when the chemically bonded oxygen exists on it various forms of functional groups $[30,31]$. The rule of surface functionalities increase significantly relative to the pore size distribution of BET surface area, and in many cases dominates [32]. Hence, microwave assisted synthesis of MWCNTs have a some functional group present on the surface of MWCNTs. In this study have achieved and outstanding adsorption capacity was achieved compared to modified CNTs which was reported in previous study [33-35]. Fig. 2(a) and (b) demonstrates the plot for optimized condition of MWCNTs before and after adsorption of $\mathrm{Cd}(\mathrm{II})$. Fig. 2(a) The peaks observed on before MWCNTs adsorption at a range of $1700-1900 \mathrm{~cm}^{-1}$ defines the carboxylic group, followed by aromatic $\mathrm{C}=\mathrm{C}$ groups at $1450-$ $1600 \mathrm{~cm}^{-1}$ and $\mathrm{O}-\mathrm{H}$ groups at $2800-3000 \mathrm{~cm}^{-1}$ as well. This observation was observed as grown MWCNTs, a very small amount of oxygen group present on the surface of MWCNTs due to synthesis condition to enhance high quality and high purity of MWCNT. Fig. 2(b) shows after adsorption of Cd(II), it was observed several peaks were observed. The $\mathrm{C}=\mathrm{O}$ and $\mathrm{C}-\mathrm{O}$ is stretching frequencies shifted from 1705 and $1200 \mathrm{~cm}^{-1}$. Peaks at $1600 \mathrm{~cm}^{-1}$ of amino-functionalized MWCNTs are due to the $\mathrm{N}-\mathrm{H}$ stretching of amine groups. Peaks at 2930 and $2860 \mathrm{~cm}^{-1}$ are greatly enhanced because of the attachment of additional methyl groups. Peaks between 950 and $700 \mathrm{~cm}^{-1}$ are due to the stretching mode of aromatic amine groups, and peaks at $2370 \mathrm{~cm}^{-1}$ may be because of the existence of ammonium ions [36-38]. After adsorption of Cd(II) process would create an open end to the MWCNTs where additional functional groups such as carboxylic group would

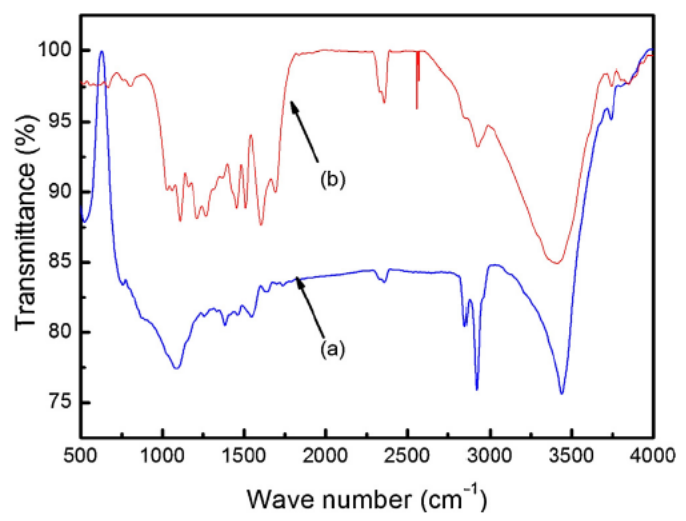

Fig. 2. FTIR adsorption spectra for (a) MWCNTs before (b) MWCNTs after adsorption of $\mathrm{Cd}(\mathrm{II})$. attach to it or any available defect sites [6,39]. The hydrophilic surface structure provides the functionalized MWCNTs an advantage of high dispersion in water, which eventually leads to a higher adsorption capacity of $\mathrm{Cd}(\mathrm{II})$ ions from aqueous solution compared with before the adsorption of MWCNTs. This finding corresponds to many results reported by several previous researchers who studied on the surface chemistry of CNTs [36-38,40-42].

\section{Thermogravimetric analysis of MWCNTS}

The variations of the MWCNTs mass with respect to temperatures at specific time were revealed in Fig. 3. A single peak at one distinct zone, implying high purity of the MWCNTs was shown in TGA analysis. Since no other peaks are observed, so the peak corresponds to the decomposition of one element only. The weight between 50 and $100^{\circ} \mathrm{C}$ which correspond to the loss of water from the catalyst support was a very minor loss. In the range of 335$350{ }^{\circ} \mathrm{C}$ of weight loss is effected of oxidation of amorphous carbon [43-45] and the weight loss in the range of $480-620^{\circ} \mathrm{C}$ is due to oxidation of MWCNTs [44]. The metal catalyst and support are not volatile below $800{ }^{\circ} \mathrm{C}$ and thus remain as residue of TGA was revealed in the observed flat profiles between 620 and $850{ }^{\circ} \mathrm{C}$. The purity and yield of MWCNTs was shown by the weight loss and as the higher the weight loss, as the higher is the purity of MWCNTs. Hence, after sorbent adsorption of Cd(II) clearly confirm the stability of MWCNTs. The previous research [23,46,47] was verified by the above finding.

\section{Statistical optimization of removal of Cd(II) using MWCNTS}

In order to determine the most suitable adsorbent with the highest adsorption capacity of Cd(II) from aqueous solutions, the first crucial step would be to determine the optimized condition of MWCNTs as a the adsorbent for removal of Cd(II). Specific runs for the optimized condition were conducted based on the design obtained from the (DOE). The results obtained from this particular experiment were analysed using the application of "analysis of variance" (ANOVA) obtained from the DOE and the optimized variables are attainable from Table 1 . The analyses obtained by the application of ANOVA for the removal of Cd(II) using MWCNTs are indicated in Table 2. From the values obtained in Table 2, the fisher $F$-test value can be related to the mean square of the regressed model which leads to the comparative mean square of the residuals (errors). The $F$ value proves the efficiency of the model as its value increases. On the other hand, low probability, $P$ value indicates higher significance of the regression model. Hence, from Table 2, it can be seen that the F-test values using MWCNTs were 19 , which indicates that the model are significant. Besides that, the

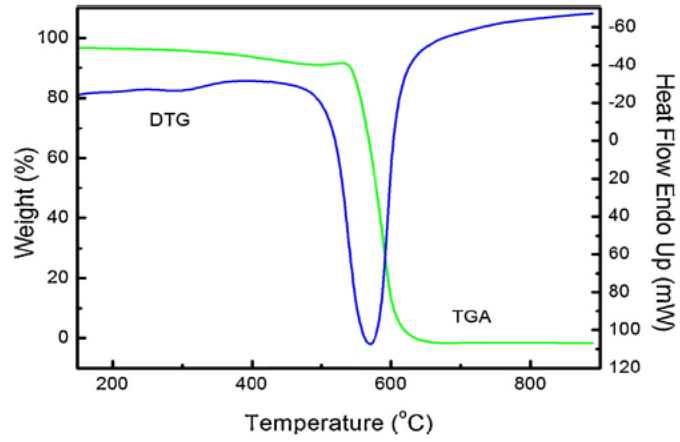

Fig. 3. TGA analysis of the MWCNTs after sorbent adsorption of Cd(II). 
Table 2

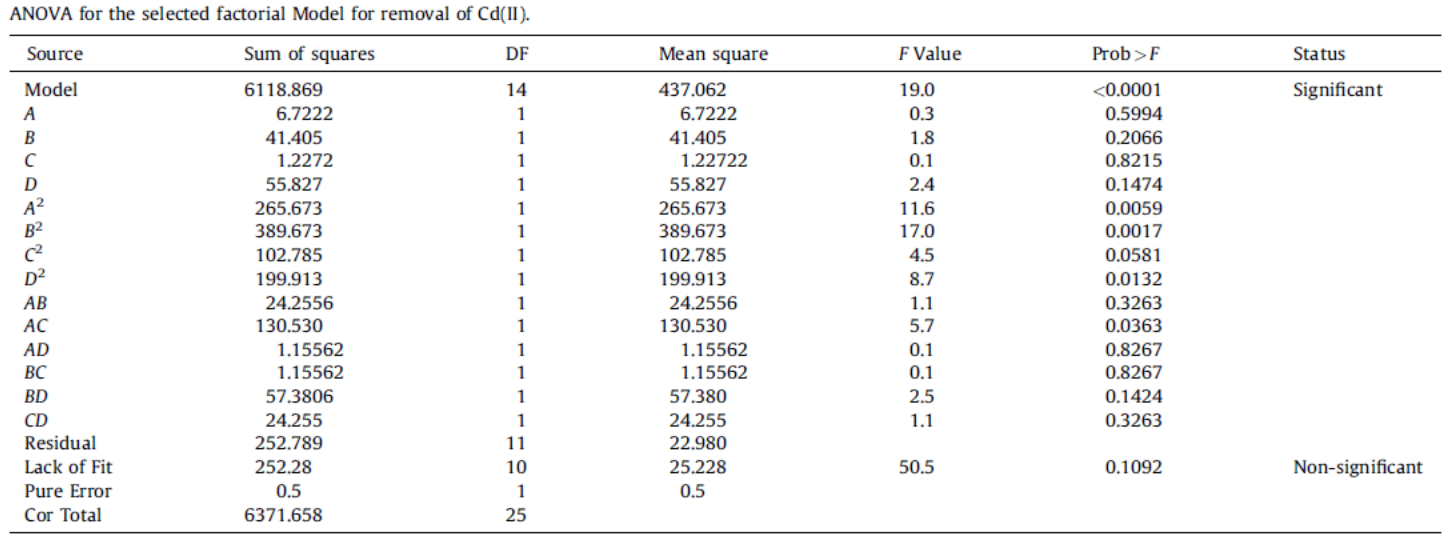

values of the correlation coefficient, $R$-squared and Adj $R$-squared for MWCNTs were 0.96 and 0.90 respectively. This value implies that the model of the adsorbent is very close to each other, which indicates the high efficiency and significance of the model. The model equation evolved for the removal of $\mathrm{Cd}(\mathrm{II})$ from aqueous solutions for MWCNTs (3) are as follows:

$$
\begin{aligned}
\text { Cd(II) Removal }(\%)= & 96.50+0.61 \times A-1.52 \times B-0.26 \\
& \times C+1.76 \times D-10.19 \times A^{2}-12.34 \\
& \times B^{2}-6.34 \times C^{2}-8.84 \times D^{2}-1.23 \\
& \times A \times B+2.86 \times A \times C+0.27 \times A \times D \\
& -0.27 \times B \times C+1.89 \times B \times D+1.23 \\
& \times C \times D
\end{aligned}
$$

Consequently, variables $A, B, C, D, A B, A C, A D, B C, B D$, and $C D$ were significant model terms. This indicates that the $\mathrm{pH}(A)$, agitation speed $(B)$, MWCNTs dosage $(C)$ and time $(D)$ were highly significant values of Probe $>F$ was 0.001 . The coefficient of single factor represents the effect of its represented factor while the coefficients of double factors represent the interaction and effect of both represented factor. Hence, following up to the equation, the positive sign in the equation represents the synergistic effect while the negative sign represents antagonistic effect values. Fig. 4 shows theoretical values versus the experimental values for Cd(II)

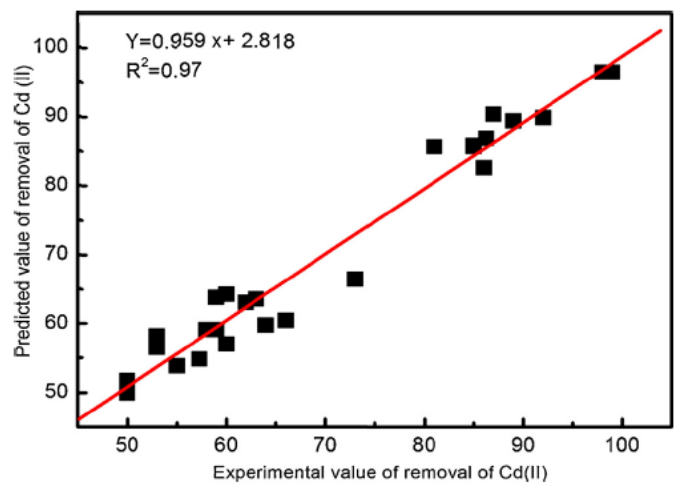

Fig. 4. Relationship between actual value vs. predicted values of removal of $\mathrm{Cd}(\mathrm{II})$. removal. It was clearly shown that the theoretical values obtained were quite close to experimental values, indicating that the model developed was successful in bridging the correlation between process parameters for removal of $\mathrm{Cd}(\mathrm{II})$.

Fig. 5 represents the 3-dimensional (3-D) plot for adsorption of $\mathrm{Cd}(\mathrm{II})$ on MWCNTs affected by $\mathrm{pH}$, MWCNTs dosage and agitation speed. The 3-D plot of the interaction between agitation speed and $\mathrm{pH}$ are as depicted in Fig. 5(a) which shows that as $\mathrm{pH}$ increases with the increasing of agitation speed, removal of $\mathrm{Cd}(\mathrm{II})$ obtained the highest at $\mathrm{pH} 5$ an $160 \mathrm{rpm}$ agitation speed gave maximum removal of $\mathrm{Cd}(\mathrm{II})$. Further increase in $\mathrm{pH}$ and agitation speed resulted in decreased $\mathrm{Cd}$ (II) removal. This is due to the effects of precipitation of $\mathrm{Cd}(\mathrm{II})$ at relatively high values of $\mathrm{pH}$ (alkaline condition). The value of $\mathrm{pH}$ of the aqueous solution plays a major role in the adsorption of heavy metals $[1,10,11]$ Fig. 5 (b) shows the interaction between $\mathrm{pH}$ and MWCNTs dosage where it was observed that removal of $\mathrm{Cd}(\mathrm{II})$ reached to the maximum when the $\mathrm{pH}$ and MWCNTs dosage is at its centre point. Further increased in $\mathrm{pH}$ and MWCNTs dosage resulted in $\mathrm{Cd}(\mathrm{II})$ adsorption decreased. From the observation, increased in MWCNTs dosage from 0.05 to 0.1 increase the removal of $\mathrm{Cd}(\mathrm{II})$ linearly. Furthermore, the increase in the adsorbed amount leads to increase in active sites concentration which helps in adjusting the adsorption solution electrostatic charge to an adsorption preferable level by removing the competitive $\mathrm{H}^{+}$ions $[10,48]$. On the other hand, the adsorption capacity is highly dependent on the $\mathrm{pH}$ where $\mathrm{H}_{2} \mathrm{O}_{2}$ oxidizes the MWCNTs to reach an equilibrium state with a high adsorption capacity at lower pH [10]. Fig. 5(c) shows the interaction between time and $\mathrm{pH}$. The elliptical plot indicated that there is good interaction between time and $\mathrm{pH}$. The mid-point interaction for a time and $\mathrm{pH}$ shows the highest removal of $\mathrm{Cd}(\mathrm{II})$ obtained. Further increase in time 35-60 min and pH 5 to 6 resulted in decreased of Cd(II) removal [49].

Adsorption isotherm

Adsorption isotherm reflects the relationship between the amount of a solute adsorbed at constant temperature and its concentration in the equilibrium solution. It provides essential physicochemical data for assessing the applicability of the adsorption process as a complete unit operation. The successful representation of the dynamic adaptive separation of solute from solution onto an adsorbent depends upon a good description of the equilibrium separation between the two phases [9,12,50-52]. The relation between contact time (min) versus adsorption capacity

\section{Link to Full-Text Articles :}

\section{http://www.sciencedirect.com/science/article/pii/S1226086X14004468}


http://ac.els-cdn.com/S1226086X14004468/1-s2.0-S1226086X14004468- main.pdf? tid=3a74d4f4-4010-11e59ddc-00000aab0f6c\&acdnat $=14392875942$ 2b6cfd4beb1e932aa9f491a04ec84b78 